\title{
Evaluation of efficiency of sire model and animal model in Holstein Friesian crossbred cattle considering first lactation production and fertility traits
}

\author{
Shakti Kant Dash ${ }^{1}$, Ashok Kumar Gupta ${ }^{1}$, Avtar Singh ${ }^{1}$, Atish Kumar Chakravarty ${ }^{1}$, Manoj Madhusoodanan ${ }^{2}$, \\ Jamuna Valsalan ${ }^{1}$, Pushp Raj Shivahre ${ }^{1}$ and Altaf Hussain ${ }^{1}$
}

1. Dairy Cattle Breeding Division, National Dairy Research Institute, Karnal - 132 001, Haryana, India; 2. Department of Animal Breeding, Genetics \& Biostatistics, CO\&AS, Trissur, Kerala, India.

Corresponding author: Shakti Kant Dash, Present address: Department of Animal Genetics and Breeding, College of Veterinary Science, GADVASU, Ludhiana, Punjab, India. e-mail: shaktikant07@gmail.com,

AKG: guptaak2009@gmail.com, AS: avtar54@gmail.com, AKC: ak_chakravarty@yahoo.co.in, MM: manojanchuvilayil@ yahoo.co.in, JV: jamunavalsalan@gmail.com, PRS: drpr06@gmail.com, AH: paltaf13@gmail.com

Received: 27-07-2014, Revised: 28-09-2014, Accepted: 04-10-2014, Published Online: 09-11-2014

doi: 10.14202/vetworld.2014.933-937. How to cite this article: Dash SK, Gupta AK, Singh A, Chakravarty AK, Madhusoodanan M, Valsalan J, Shivahre PR, Hussain A (2014) Evaluation of efficiency of sire model and animal model in Holstein Friesian crossbred cattle considering first lactation production and fertility traits, Veterinary World 7(11): 933-937.

\begin{abstract}
Aim: The present investigation was conducted for evaluating the efficacy of estimating breeding values (BVs) using univariate animal model in comparison to sire model. The various parameters considered for evaluating the efficiency of both linear models were coefficient of determination $\left(\mathrm{R}^{2}\right)$, coefficient of variation $(\mathrm{CV})$, within sire variance or error variance and spearman's rank correlation estimates.

Materials and Methods: Data for the present investigation were spread over a period of 34 years from 1978 to 2012 and consisted of a total of 1988 lactation records of Holstein Friesian crossbred cows sired by 186 crossbred bulls.

Results: The percentage of sires having BV (estimated by animal model) more than the average BV for the traits viz. age at first calving (AFC), first service period (FSP), first lactation length (FLL), first calving interval (FCI), first lactation 305 day milk yield (F305MY), first lactation total milk yield (FTMY), milk yield per day of first lactation length (MY/FLL) and milk yield per day of first calving interval (MY/FCI) were 48.05, 49.39, 55.07, 49.21, 50.00, 51.39, 48.67, 50.39\%, respectively. The animal model had higher $\mathrm{R}^{2}$, lower CV and error variance for most of the fertility and production traits. The spearman's rank correlation estimates indicated similarity of rankings by both the linear models as the animal model is an improvement of sire model.
\end{abstract}

Conclusion: Animal model had a wider range of BVs indicating the greater differentiating ability of the model. Based on $\mathrm{R}^{2}, \mathrm{CV}$ and error variance animal model was found to be superior in comparison to sire model.

Keywords: animal model, breeding value, efficiency, sire model.

\section{I ntroduction}

Enhancing productive potential of the dairy cattle is of primary importance for the animal breeder. In the overall genetic improvement of a trait, the sire path contributes greatly in comparison to the dam path due to higher intensity of selection [1]. Use of high genetic merit bulls in artificial insemination would bring higher genetic progress when bulls are evaluated by an effective method of selection. Selection of dairy animals is basically carried out using linear and nonlinear models of genetic evaluation and the sires are ranked on the basis of production performance of its daughters.

Selection of dairy bulls using conventional methods (such as the contemporary comparison of sire evaluation) has long been carried out under Indian conditions. These methods of sire evaluation do not take into account the relationships between the

Copyright: The authors. This article is an open access article licensed under the terms of the Creative Commons Attributin License (http:// creative commons.org/licenses/by/2.0) which permits unrestricted use, distribution and reproduction in any medium, provided the work is properly cited. individuals of the population on which observations have been made [2]. Therefore, use of advanced linear models needs to be carried out for accurate estimation of breeding values (BVs) giving emphasis to the relationship between the individuals of the population. Both sire and animal model include the numerator relationship matrix (NRM), which takes into account the relationship and inbreeding coefficient of the individuals of the population. However in sire model, it is assumed that the mates are of equal merit which could result in biased estimates of BVs [3].

The present investigation was carried out with the objective of determining which linear model (sire or animal) holds good for sire evaluation in Holstein Friesian crossbred cattle under Indian conditions. Univariate sire evaluation was carried out for both fertility and production traits and comparison between the sire rankings for fertility and production traits was observed for confirming whether the negative association of fertility and production traits also affected the ranking of the sires. 


\section{Materials and Methods}

\section{Ethical approval}

The present investigation did not require ethical approval as only pheneotypic records were used for investigation. The study was non-invasive and non-interactive, with no element of intervention causing any type of stress to the animals.

The data collected for the present investigation on production and fertility performance of HolsteinFriesian crossbred cattle was spread over a period of 34 years (1978-2012). The data consisted of over 1787 records of first lactation traits. The data were collected from NDRI farm situated in the TransGangetic plain, in the eastern zone of Haryana. The fertility traits considered for analysis were AFC, FSP, FCI, FLL and the production traits considered in the study were F305MY, FTMY, MY/FLL and MY/FCI.

The standard management practices regarding the housing, feeding, milking and breeding were followed at this farm. Cows were bred by artificial insemination, after detection of females in heat. The breeding policy up to 1970 was to select bulls from high yielding dams. Since 1970, the breeding policy was followed as per the recommendations of All India Co-Ordinated Research Project on cattle breeding. Initially, young male calves born to elite dams are raised on the farm and selected for inclusion in the set of progeny testing on the basis of their expected predicted difference, growth, health, libido, semen quality and freez ability of semen. The cows in the elite group were mated to top ranking bulls, and their male progenies were reared as future young sires.

The nutritional requirements were met through a balanced ration of green, dry fodder and concentrates. The calves were weaned at birth and fed colostrums of its own dam up to 4-5 days and later on whole milk up to 30 days. Beyond this age they were fed on different proportions of whole milk, skim milk and skim milk up to 6 months. Minerals, concentrates and roughages are available to the calves from 1 month of age and fed according to the body weight as per nutritional standards. During later age, feeding schedules are laid down according to age groups considering the requirements of maintenance, growth, reproduction and production.

The housing system of the cows consisted of loose housing system, with separate sheds being provided for each category (young, dry, lactating and down calvers) of animals. The young stock was housed according to age group, i.e., the animals from birth to 6 months, 6 months to 2 years and heifer from 2 years to conception were kept in different sheds. The animals were protected from adverse climatic conditions. The calves were kept in covered calf pens up to 6 months of age and thereafter in loose housing system.

\section{Sire model}

Henderson developed the mixed model equation (MME) that is the best linear unbiased estimator
(BLUE) of the fixed effects and best linear unbiased predictor (BLUP) of the random effects. The MME forms the basis for a solution of linear mixed model. The advantage of this MME was that it could account for the relationship between the individuals of the population by the NRM. The sire model takes the relationship only between the sires into account.

$\mathrm{y}=\mathrm{Xb}+\mathrm{Za}+\mathrm{e}$

Where,

$\mathrm{y}=\mathrm{n} \times 1$ observation vector of the fertility or production trait

$\mathrm{X}=$ Incidence matrix for fixed effects of the order $\mathrm{n} \times \mathrm{p}$

$\mathrm{b}=\mathrm{p} \times 1$ vector for fixed effects

$\mathrm{Z}=$ Incidence matrix for random effect with dimension $\mathrm{n} \times \mathrm{q}$

$\mathrm{a}=\mathrm{q} \times 1$ vector of random effect

$\mathrm{e}=\mathrm{n} \times 1$ vector of random residual effects with mean 0 and variance $\sigma_{\mathrm{e}}^{2}$.

The solution of linear models of BLUP will result in the following MMEs:

$\left[\begin{array}{cc}X^{\prime} X & X^{\prime} Z \\ Z^{\prime} X & Z^{\prime} X+A^{-1} \alpha\end{array}\right]\left[\begin{array}{l}\hat{b} \\ \hat{a}\end{array}\right]=\left[\begin{array}{l}X^{\prime y} \\ Z^{\prime} y\end{array}\right]$

Where, $\alpha=\sigma_{\mathrm{e}}^{2} / 0.25 \sigma_{\mathrm{a}}^{2}$, the MMEs the BV of the random effects was estimated [4].

\section{Animal model}

The animal model is an advancement of the sire model; it has become the international basis for BV estimation of all the animals in a population. The animal model which is a set of many different models, NRM (A) computed from pedigree information accounts for all the information about known relationships among the animals in a population. This helps the animal model to predict each animal's genetic merit [4]. The linear model for describing animal model is similar to sire model, and the terms are similar to the ones defined in equation of sire model;

$\mathrm{y}=\mathrm{Xb}+\mathrm{Za}+\mathrm{e}$

The MME for animal model becomes;

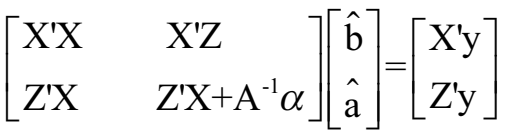

Where, $\alpha=\sigma^{2} / \sigma^{2}$, and A is the NRM of all the animals, which has nonzero off-diagonals only for the animal's parents, progeny, and mates. The elements of A can contain additive genetic effects, non-additive genetic effects, maternal effects, and permanent environmental effects [4]. 


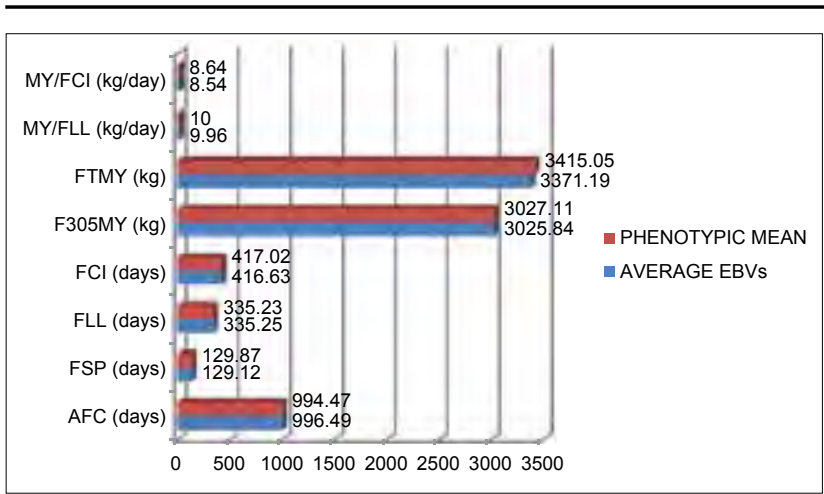

Figure-1: Comparison between the mean expected breeding values and the average phenotypic values for production and fertility traits.

\section{Results}

The mean estimates of expected BVs (EBVs) for production and fertility traits were similar to the average phenotypic values of the traits, indicating the EBVs had a similar distribution as the phenotypic data (Figure-1 and Table-1). Percentage of sires whose BV was more than the mean BV (estimated by animal model) were 48.05\% (AFC), 49.39\% (FSP), 55.07\% (FLL), 49.21\% (FCI), 50\% (F305MY), 51.39\% (FTMY), 48.67\% (MY/ FLL), 50.39\% (MY/FCI) (Table-2).

Selection of best univariate model for prediction of EBV was done on the basis of coefficient of determination $\left(\mathrm{R}^{2}\right)$, coefficient of variation (CV), within sire variance or error variance and spearman's rank correlation estimates. The results of the analysis obtained trait wise are discussed below.

The estimates of $\mathrm{R}^{2}$ of the animal model for fertility traits AFC (38.47\%), FSP (24.13\%) and FCI $(10.60 \%)$ were substantially higher than the $\mathrm{R}^{2}$ estimates of sire model. Similar findings were also observed in the case of production traits (Table-3).

The relative efficiency (RE) estimates of animal model in case of fertility traits ranged from $88.42 \%$ (AFC) to $96.41 \%$ (FCI) and in case of production traits ranged from $80.28 \%$ (MY/FCI) to $94.71 \%$ (FTMY). Greater RE of the animal model was observed in the case of production traits (F305MY and FTMY) in comparison to production efficiency traits (MY/FLL and MY/FCI) (Table-4).

Spearman's rank correlation estimates for fertility traits ranged from 0.85 (FCI) to 0.93 (AFC). Rank correlation estimates for production traits were also high ranging from 0.87 (FLL) to 0.90 (F305MY). Very strong correlation was observed between sire and animal model rankings in case of production efficiency traits (Table-5).

\section{Discussion}

BVs estimated by sire model lack precision as only the relationship between the sires is taken into account. Sire model is based on the assumption that all the progeny are from different dams and all dams are from different populations with the same expected mean. In practice, dams may be selected over time
Table-1: Data structure and descriptive statistics of first lactation production and fertility traits.

\begin{tabular}{lcccc}
\hline Trait & $\begin{array}{c}\text { Number } \\
\text { of records }\end{array}$ & Mean & SE & CV\% \\
\hline AFC (days) & 1787 & 994.47 & 3.03 & 12.90 \\
FCFS (days) & 744 & 83.21 & 1.37 & 44.82 \\
FSP (days) & 1015 & 129.87 & 2.01 & 49.23 \\
FLL (days) & 1580 & 335.23 & 2.39 & 28.32 \\
FCl (days) & 1170 & 417.02 & 2.34 & 19.18 \\
F305MY (kg) & 1553 & 3027.11 & 20.31 & 26.43 \\
FTMY (kg) & 1596 & 3415.05 & 31.96 & 37.39 \\
MY/FLL (kg/day) & 1574 & 10.00 & 0.05 & 21.44 \\
MY/FCl (kg/day) & 1223 & 8.64 & 0.06 & 23.63 \\
\hline
\end{tabular}

$\mathrm{SE}=\mathrm{Standard}$ error, $\mathrm{CV}=$ Coefficient of variation, $\mathrm{AFC}=$ age at first calving, FCFS =first lactation calving at first service, $\mathrm{FSP}=$ first service period, $\mathrm{FLL}=$ first lactation length, $\mathrm{FCl}=$ first calving interval, $\mathrm{FTMY}=$ first lactation total milk yield, MY/FLL=milk yield per day of first lactation length, $\mathrm{MY} / \mathrm{FCl}=$ milk yield per day of first calving interval, F305MY=First lactation 305 day milk yield, FTMY $=$ first lactation total milk yield

Table-2: Range of EBVs estimated by sire and animal model for first lactation production and fertility traits.

\begin{tabular}{lcc}
\hline \multirow{2}{*}{ Traits } & \multicolumn{2}{c}{ Range } \\
\cline { 2 - 3 } & Sire model & Animal model \\
\hline AFC (days) & 130.00 & 168.00 \\
FSP (days) & 27.00 & 53.00 \\
FLL (days) & 25.00 & 18.00 \\
FCl (days) & 7.20 & 35.00 \\
F305MY (kg) & 640.34 & 1101.28 \\
FTMY (kg) & 553.86 & 772.43 \\
MY/FLL (kg/day) & 1.87 & 2.97 \\
MY/FCl (kg/day) & 2.14 & 3.82 \\
\hline
\end{tabular}

$\mathrm{EBV}=$ Expected breeding values, $\mathrm{AFC}=$ At first calving, $\mathrm{FSP}=$ First service period, $\mathrm{FLL}=$ First lactation length, $\mathrm{FCl}=$ First calving interval, $\mathrm{FTMY}=$ First lactation total milk yield, MY/FLL=Milk yield per day of first lactation length, $\mathrm{MY} / \mathrm{FCl}=$ Milk yield per day of first calving interval, F305MY=First lactation 305 day milk yield, FTMY=first lactation total milk yield

Table-3: Effectiveness of univariate sire evaluation models for prediction of BVs for first lactation traits, based on the $\mathrm{R}^{2}$ and $\mathrm{CV}$.

\begin{tabular}{lcclcc}
\hline Traits & \multicolumn{2}{c}{$\mathbf{R}^{\mathbf{2}}$ (\%) } & & \multicolumn{2}{c}{$\mathbf{C V}(\%)$} \\
\cline { 2 - 3 } \cline { 5 - 6 } & $\begin{array}{c}\text { Sire } \\
\text { model }\end{array}$ & $\begin{array}{c}\text { Animal } \\
\text { model }\end{array}$ & & $\begin{array}{c}\text { Sire } \\
\text { model }\end{array}$ & $\begin{array}{c}\text { Animal } \\
\text { model }\end{array}$ \\
\hline AFC & 17.70 & 38.47 & & 11.43 & 10.75 \\
FSP & 8.30 & 24.13 & & 48.11 & 46.15 \\
FCl & 3.60 & 10.60 & & 18.82 & 18.48 \\
FLL & 3.40 & 4.89 & & 27.74 & 27.76 \\
F305MY & 12.90 & 40.13 & & 24.09 & 22.05 \\
FTMY & 5.50 & 17.11 & & 36.70 & 35.72 \\
MY/FLL & 16.70 & 40.03 & & 19.53 & 18.16 \\
MY/FCl & 14.10 & 46.85 & & 21.46 & 19.22 \\
\hline
\end{tabular}

$\mathrm{CV}=$ Coefficient of variation, $\mathrm{AFC}=$ At first calving, $\mathrm{FSP}=$ First service period, $\mathrm{FLL}=$ First lactation length $\mathrm{FCl}=$ First calving interval, $\mathrm{FTMY}=$ First lactation total milk yield, MY/FLL=Milk yield per day of first lactation length, $\mathrm{MY} / \mathrm{FCl}=$ Milk yield per day of first calving interval, F305MY=First lactation 305 day milk yield, FTMY=first lactation total milk yield, BV=Breeding values

making younger dams better than older dams (3). In sire model, the sires were assumed to be unrelated and 
Table-4: Effectiveness of univariate sire evaluation models for prediction of BVs for first lactation traits, based on error variance and RE.

\begin{tabular}{lcccc}
\hline Traits & \multicolumn{2}{c}{ Error variance } & & RE (\%) \\
\cline { 2 - 3 } \cline { 5 - 5 } & Sire model & $\begin{array}{c}\text { Animal } \\
\text { model }\end{array}$ & & $\begin{array}{c}\text { Animal model/ } \\
\text { sire model }\end{array}$ \\
\hline AFC & 12966.83 & 11465.30 & & 88.42 \\
FSP & 3828.39 & 3523.16 & & 92.03 \\
FCl & 6114.77 & 5895.21 & 96.41 \\
\hline & & & Sire model/ \\
& & & animal model \\
\hline FLL & 8636.91 & 8648.71 & & 99.86 \\
\hline & & & Animal model/ \\
& & & sire model \\
\hline F305MY & 534448.72 & 447933.00 & & 83.81 \\
FTMY & 1522595.58 & 1442020.00 & & 94.71 \\
MY/FLL & 3.78 & 3.27 & & 86.53 \\
MY/FCl & 3.39 & 2.72 & 80.28 \\
\hline AFC & & & & \\
\hline
\end{tabular}

$\mathrm{AFC}=$ At first calving, $\mathrm{FSP}=$ First service period, $\mathrm{FLL}=$ First lactation length, $\mathrm{FCl}=$ First calving interval, $\mathrm{FTMY}=$ First lactation total milk yield, MY/FLL=Milk yield per day of first lactation length, $\mathrm{MY} / \mathrm{FCl}=$ Milk yield per day of first calving interval, F305MY=First lactation 305 day milk yield,

FTMY=first lactation total milk yield, RE=Relative efficiency

Table-5: Rank correlation $\left(r_{s}\right)$ estimates based on EBVs of first lactation traits estimated from univariate SLS, sire model and animal model.

\begin{tabular}{lc}
\hline Traits & Rank correlation $\left(\mathbf{r}_{\mathbf{s}}\right)$ \\
\hline AFC & $0.93^{* *}$ \\
FSP & $0.91^{* *}$ \\
FCl & $0.85^{* *}$ \\
FLL & $0.87^{* *}$ \\
F305MY & $0.90^{* *}$ \\
FTMY & $0.89 * *$ \\
MY/FLL & $0.91^{* *}$ \\
MY/FCl & $0.96 * *$ \\
\hline
\end{tabular}

$* *$ Indicates highly significant at $\mathrm{P}<0.01, \mathrm{EBV}=\mathrm{Expected}$ breeding values, $A F C=A$ t first calving, $F S P=$ First service period, $\mathrm{FLL}=$ First lactation length, $\mathrm{FCl}=$ First calving interval, FTMY=First lactation total milk yield, MY/FLL=Milk yield per day of first lactation length, $\mathrm{MY} / \mathrm{FCl}=$ Milk yield per day of first calving interval, F305MY=First lactation 305 day milk yield, FTMY=first lactation total milk yield, SLS=Simple least squares

for animal model the relationship among all the individuals in the population was taken into account. The (co) variance components estimated by average information maximum likelihood method were utilized in univariate animal models for prediction of EBVs.

The estimates indicated that around half of the sires for most of the production and fertility traits had EBVs more than the mean EBVs. This implied the existence of greater additive variability amongst the sires in the herd. This may be due to the result of decreased culling of low producing daughters from the herd (for maintenance of herd strength) which reflected in the presence of low-performing sires. The range of EBVs by animal model was higher than EBVs by sire model estimated for almost all the traits (excepting FLL), indicating greater differentiating ability of the animal model [5].
The $\mathrm{R}^{2}$ estimates indicated that the animal model had better fit than the sire model for the present data set. Animal model had lower CV\% (CV) than the sire model which indicated the greater stability of the model for both production and fertility traits. BLUP animal model was more efficient in comparison to other methods of sire evaluation which has been observed in various reports [5-8].

The error variance estimate of the linear model indicates its accuracy in prediction of BVs. In comparison to sire model, the animal model had lower error variance and superior estimates of RE. The findings of the present investigation were similar to the report observing that the animal model had lower error variance in comparison to conventional methods of BV estimation [9].

Sire model had lower error variance and greater RE incase of FLL this may be due the fact that sire model has the advantage of increasing the information per animal which could be useful in populations with low information. The strong correlation between the rankings of sire and animal model can be attributed to the fact that animal model is an advancement of sire model which considers the relationship between all the individuals of a population [10].

\section{Conclusion}

The present study revealed that the animal model in comparison to sire model had greater accuracy in prediction of BVs for first lactation fertility and production traits in Holstein-Friesian crossbred cattle.

\section{Authors' Contributions}

AKG, AS, and AKC designed the experiment. SKD carried out the data collection, data analysis and manuscript preparation with support of MM, JV, PRS, and AH. Manuscript was reviewed and edited by AKG. The final manuscript was read and approved by all the authors.

\section{Acknowledgments}

The authors express their sincere gratitude to the Head, Dairy Cattle Breeding Division and Director, National Dairy Research Institute, Karnal for providing the funds and research facilities for the successful completion of this study.

\section{Competing I nterests}

The authors declare that they have no competing interests.

\section{References}

1. Banik, S. and Gandhi, R.S. (2010) Sire evaluation using single and multiple trait animal models in Sahiwal cattle. Indian J. Anim. Sci., 80: 269-270.

2. Sun, C., Madsen, P., Lund, M.S., Zhang, Y., Nielsen, U.S. and Su, G. (2010) Improvement in genetic evaluation of female fertility in dairy cattle using multiple-trait models including milk production traits. J. Anim. Sci., 88: 871-878.

3. Mrode, R.A. Linear Models for the Prediction of 
Animal Breeding Values. $2^{\text {nd }}$ ed. CAB International, Wallingford, UK.

4. Henderson, C.R. (1988) Theoretical basis and computational methods for a number of different animal models. J. Dairy. Sci., 71: 1-16.

5. Dubey, P.P., Singh, C.V., Prasad, R.B. (2006) Relationship between sire's estimated breeding values for first lactation and lifetime traits and ranking of sires in Sahiwal and its cross. Indian J. Anim. Sci., 76: 824-828.

6. Bajetha, G. (2006) Selection of sires by using different sires evaluation methods in crossbred cattle. PhD, GB Pant University of Agriculture \& Technology, Pantnagar, Uttarakhand, India.

7. Moges, T.G., Singh, C.V., Barwal, R.S., Kumar, D. and
Singh, C.B. (2009) Evaluation of sires using different multipart sire evaluation methods in crossbred cattle. Indian J. Dairy. Sci., 62: 1-4.

8. Singh, V.K. and Singh, C.V. (2011) Sire evaluation using animal model and conventional methods for milk production in crossbred cattle. Indian J. Anim. Sci., 81: 77-79.

9. Jain, A.K. and Sadana, D.K. (2000) Sire evaluation using animal model and conventional methods in Murrah Buffaloes. Asian Aust. J. Anim. Sci., 13: 1196-1200.

10. Gutierrez, J.P., Canon, J. and Goyache, F. (1997) Estimation of direct and maternal genetic parameters for preweaning traits in the Asturiana de los Valles beef cattle breed through animal and sire models. J. Anim. Breed. Genet., 114: 261-266.

$* * * * * * * *$ 